\title{
Study on removal of iron and manganese from groundwater with resin Jie Yun ${ }^{1} \&$ Yan Zhang ${ }^{1} \&$ YaShu Yuan ${ }^{1} \& \mathrm{NaNa} \mathrm{Wu}^{1}$ \& Zhen Fang ${ }^{1}$ \& QingHui Fan ${ }^{1}$

\author{
${ }^{1}$ Shenyang Jianzhu university, Shenyang, Liaoning, China
}

KEYWORD: 732 cation exchange resin; Adsorption; Various filtering velocity; Low temperature; Iron and manganese

ABSTRACT: The thesis explores the adsorption of 732 cation exchange resin to remove the excessive amount of iron and manganese in the low-temperature groundwater. The removal effects in different temperature and filtering velocities are analyzed by testing the effluent water quality and measuring the volume of water sample that could be purified by resin to reach the standard. The results suggest at a range of various filtering velocities, the removal effects are almost the same, but the higher the filtering velocity is, the larger volume of the water sample up to standard is. When the filtering velocity is $5-6 \mathrm{~m} / \mathrm{h}$, the volume is $3000 \mathrm{ml}$, but when the filtering velocity is $12-13 \mathrm{~m} / \mathrm{h}$, it is $4500 \mathrm{ml}$. As the temperature goes down, the removal effect reduces, and the volume of the water sample purified also decreases. At $4-5^{\circ} \mathrm{C}$, the volume is $3500 \mathrm{ml}$, while at $15-20^{\circ} \mathrm{C}$, it is $4500 \mathrm{ml}$.

\section{INTRODUCTION}

Groundwater resources in china are abundant and quality-stabilized. However, the concentration s of iron and manganese, usually existing in the form of Fe(II) and $\mathrm{Mn}(\mathrm{II})$, in groundwater exceed the standard in most regions. The traditional ways to remove iron and manganese are in low efficiency, and could not guarantee the effluent water quality. A moderate amount of iron or manganese does no harm to people's health, even have benefit. However, long-term imbibing excessive amount of iron and manganese may lead to chronic intoxication. The large amount of extra iron accumulating in the human body may injure gland, liver and skin. And the large amount of extra manganese may hurt the central nervous system, and even cause some endemic disease, like rickets. The traditional methods of removing iron and manganese from groundwater include natural oxidation, contact oxidation, biological oxidation, medicinal oxidation, and absorbing method. However, the costs are high and the operations are complex.

With the development of modern organic synthesis industry recently, more and more high-quality ion exchange resins appear, and be applied to almost all fields of industry. Hundreds of kinds of resins are being produced around the world, and the production reaches several million tons per year. Ion exchanging methods are widely used in water advanced treatment. They could remove ions completely from the water, with good adsorption and it is environmental-friendly. Thus, it is of a great practical significance to apply the ion exchange methods to the removal of Iron and Manganese from groundwater. The 732 cation exchange resin is studied for its adsorption of Iron and Manganese, especially at different filtering velocities, and different temperatures.

\section{METHODS}

\section{Materials and instrument}

732 cation exchange resin, 721 spectrophotometer, $2 \mathrm{~cm}$-inner-diameter ion exchange column.

\section{The pretreatment of 732 cation exchange resin}

Put the newly-bought 732 cation exchange resins in distilled water until the upper liquid is clear and transparent, wash the resin using $2.0 \mathrm{~mol} / \mathrm{L} \mathrm{HCL}$ solution and $2.0 \mathrm{~mol} / \mathrm{L}$ sodium hydroxide solution respectively, then wash the resin with distilled water to be neutral, dry the resin to constant weight.

The basic property of 732 cation exchange resin: It is big hole-styrene divinyl benzene. Functional group is sulfonic group. It is non-transparent yellow spherical particles, sodium ions form. Particle size is $0.3-1.2 \mathrm{~mm}$. Wet the true density is $1.23-1.28 \mathrm{~g} / \mathrm{ml}$. Wet density is $0.75-0.85 \mathrm{~g} / \mathrm{ml}$. 


\section{Preparation of water sample}

Water sample is made with groundwater, added with chemicals to be water sample consisted with excessive amount of iron and manganese, $(\mathrm{Fe} 2.75 \mathrm{mg} / \mathrm{L}, \mathrm{Mn} 0.53 \mathrm{mg} / \mathrm{L})$. To simulate the condition of low-temperature of groundwater, put some water sample in the freezer to keep a lower temperature $\left(4-5^{\circ} \mathrm{C}\right)$.

\section{Methods}

Take $50 \mathrm{ml}$ resin after pretreatment in the ion exchange column, and control the flow of the water sample to keep a stable filtering velocity. Take a certain volume of water sample filtered at regular intervals, and test the iron and manganese concentration s. Then analyze the data using Matlab.

\section{The testing methods}

The testing methods are listed in Table 1.

Table 1. The testing methods

\begin{tabular}{lll}
\hline item & test method & test instrument \\
\hline total iron o-phenanthroline & 721 spectrophotome \\
& $\begin{array}{l}\text { speetrophotometry } \\
\text { method }\end{array}$ & ter \\
& \\
$\begin{array}{ll}\text { mangane formaldoxime } \\
\text { se photometric method }\end{array}$ & $\begin{array}{l}\text { 721 spectrophotome } \\
\text { ter }\end{array}$ \\
\hline
\end{tabular}

\section{RESULTS AND DISCUSSIONS}

At a normal temperature, test the effect of removal of the iron and manganese at different filtering velocity

Keep a range of filtering velocities of $1.3-1.5 \mathrm{~m} / \mathrm{h}, 2.5-3 \mathrm{~m} / \mathrm{h}, 3.8-4.5 \mathrm{~m} / \mathrm{h}, 5-6 \mathrm{~m} / \mathrm{h}$ respectively. Test the iron and manganese concentration of the effluent water. The results are shown in Figure 1 and Figure 2.

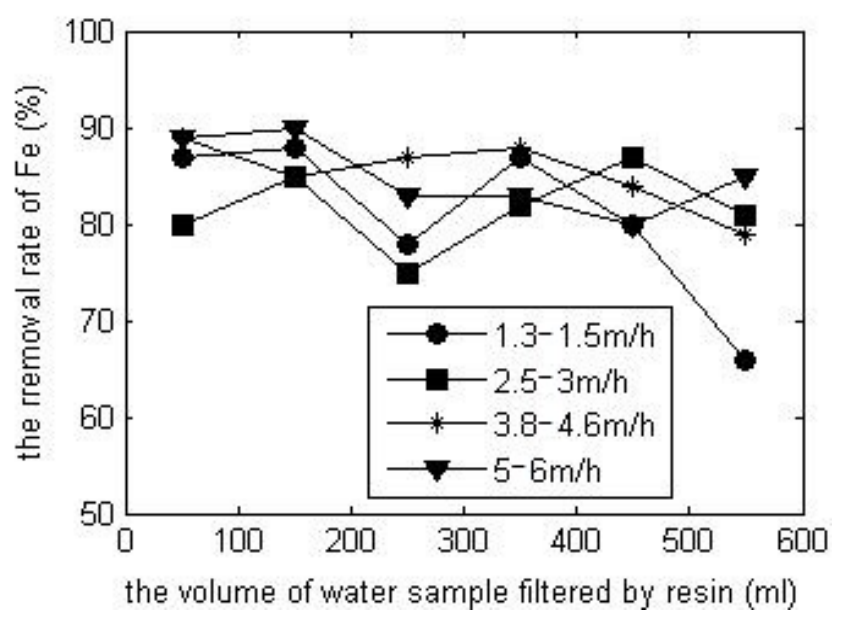

Figure 1. The relationship between the volume of water sample filtered by resin and the removal rate of $\mathrm{Fe}(\%)$ in the first experiment 


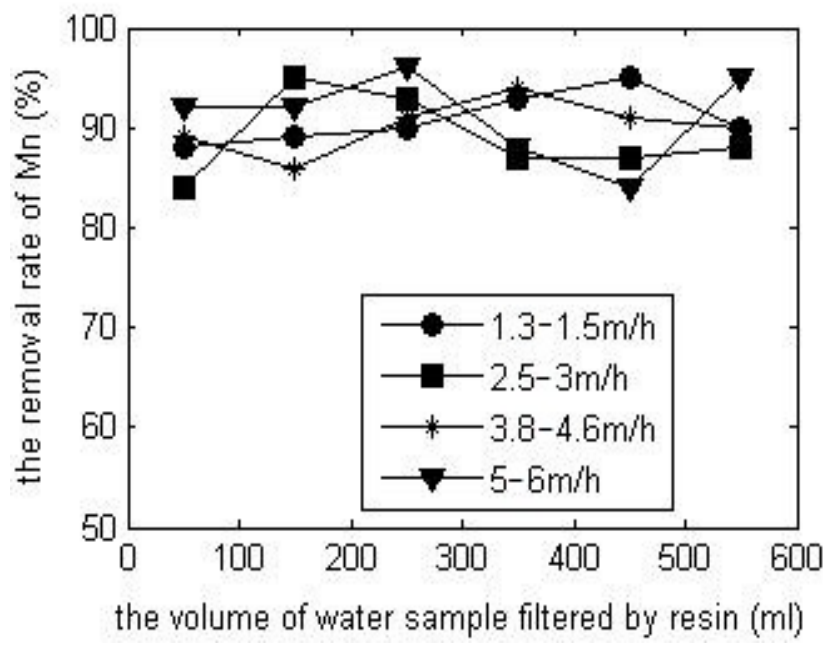

Figure 2. The relationship between the volume of water sample filtered by resin and the removal rate of $\mathrm{Mn}(\%)$ in the first experiment

From Figure 1, Figure 2, at a normal temperature, resin has an obvious removal effect of iron and manganese. At different filtration velocities, there is no significant variation of removal effect. This may be due to at the beginning of the filtering, resin's adsorption ability is strong. The amount of iron and manganese that could be absorbed per unit time can be far larger than the iron and manganese provided at biggest filtering velocity we set. The most resin at lower layer does not function. So, the filtering velocity as an influencing factor can be ignored in the tested range of filtering velocity.

\section{At a normal temperature, the volume of water could be purified to reach the standard at different filtering velocity}

Control filtering velocities of $5-6 \mathrm{~m} / \mathrm{h}$ and $12-13 \mathrm{~m} / \mathrm{h}$ until the effluent water quality tested does not meet the hygienic standards (GB5749-2006) for drinking water of iron or manganese. Select several groups of water samples during this procedure, and test the iron and manganese concentration. Then the effect of the removal at different filtering velocities could also be analyzed. The results are shown in Figure 3 and Figure 4.

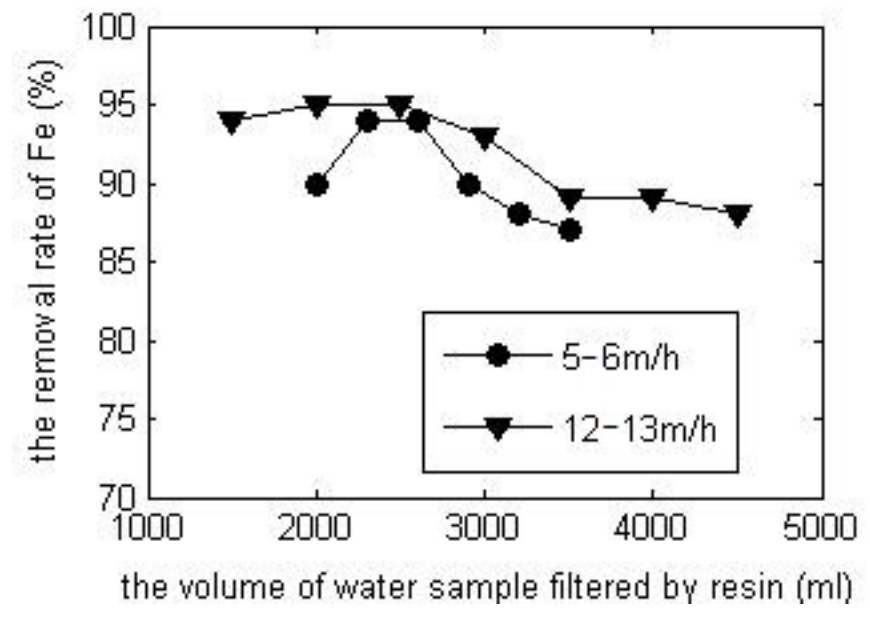

Figure 3. The relationship between the volume of water sample filtered by resin and the removal rate of $\mathrm{Fe}(\%)$ in the second experiment 


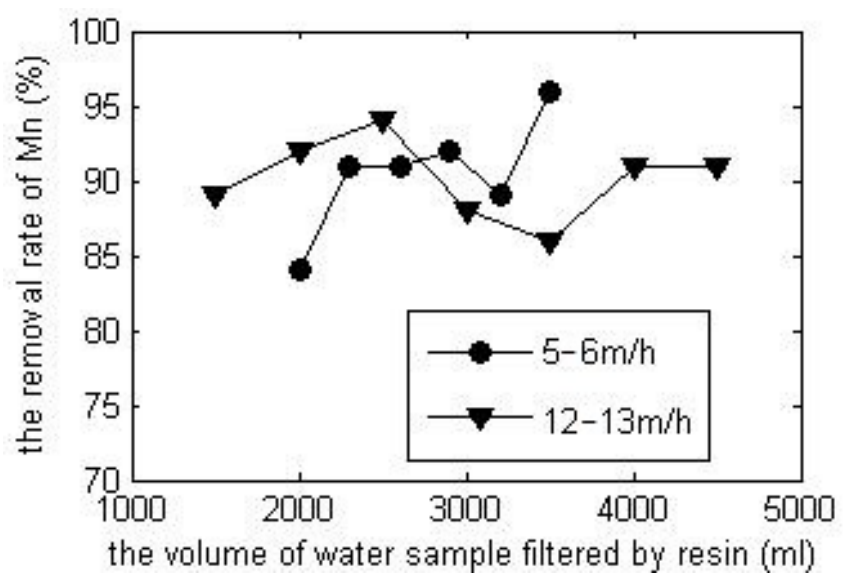

Figure 4. The relationship between the volume of water sample filtered by resin and the removal rate of $\mathrm{Mn}(\%)$ in the second experiment

From the result of the first experiment, filtering velocity has no obvious effect on effluent water quality, so select the largest filtering velocity set in the first experiment, and the largest velocity the resin column can afford.

When water sample flow through the resin at $5-6 \mathrm{~m} / \mathrm{h}$, the volume of the water sample up to standard is $3000 \mathrm{ml}$. Then the effluent water quality does not reach the standard especially considering Fe. When water samples flow through the resin filtering at $12-13 \mathrm{~m} / \mathrm{h}$, the volume is $4500 \mathrm{ml}$.

From the Figure 3 and Figure 4, along with the increase of the filtering velocity, the amount of water could be purified to reach the standard also increases. The possible reason is that in ion exchange column of larger filtering velocity, resin is fully utilized due to the large flow rate. While in ion exchange column of smaller filtering velocity, only the upper layer of resin is being used. Iron is in large size, and easy to jam surface channels of resin particles. So most of the iron molecules only adhere to the surface of the resin. When the amount of the iron molecules attaching to the iron is large enough, some parts start to get rid of the resin, flowing away along with water sample. Due to the high concentration, the lower layer resin can't absorb them entirely, leading to rapid-deterioration of effluent water. Also, at different filtration velocity, there is no significant change in removal effect of iron and manganese.

At both a normal temperature and a lower temperature $\left(4-5^{\circ} \mathrm{C}\right)$, the effect of removal of the iron and manganese and the volume of water could be purified to reach the standard are tested

Control the filtering velocity at $13-15 \mathrm{~m} / \mathrm{h}$. take $100 \mathrm{ml}$-water continuously until the water quality detected does not meet the standards level for drinking water of iron or manganese. Select several groups of water samples during the procedure, test the iron and manganese concentration s. Then the effect of the remove at different temperatures and the largest volume of the water sample that the resin could tackle to the standard level could be got and analyzed.

The results are shown in Figure 5 and Figure 6: 


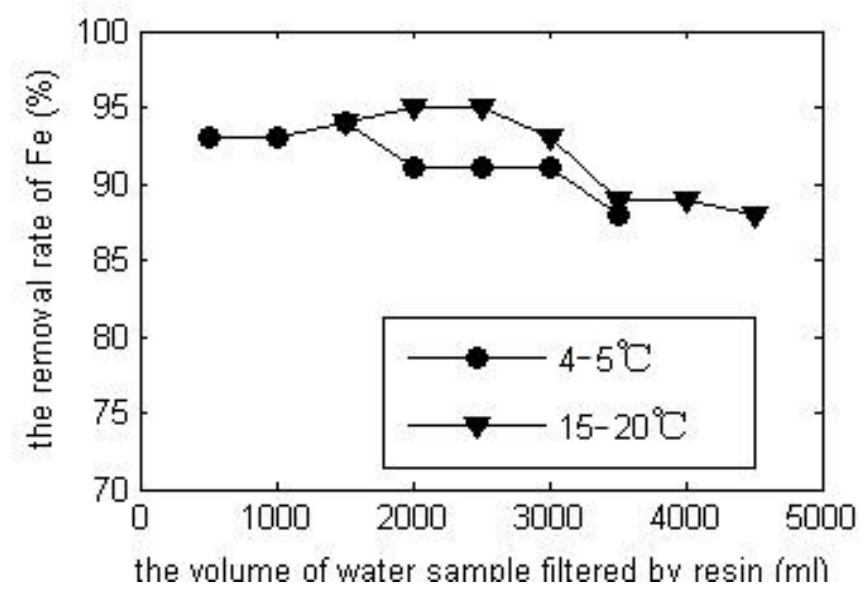

Figure 5. The relationship between the volume of water sample filtered by resin and the removal rate of $\mathrm{Fe}(\%)$ in the third experiment

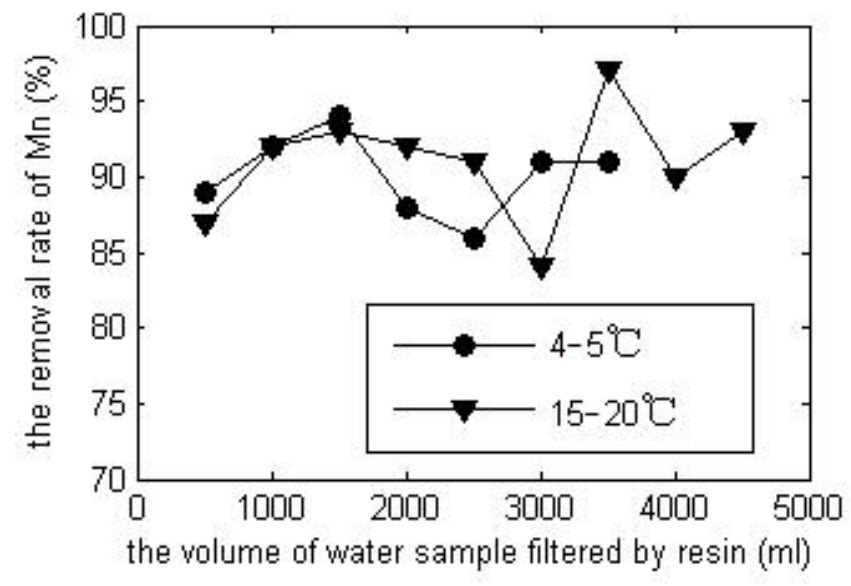

Figure 6 . The relationship between the volume of water sample filtered by resin and the removal rate of $\mathrm{Mn}(\%)$ in the third experiment

At normal temperature, when the water samples flow through the resin at $12-13 \mathrm{~m} / \mathrm{h}$, the volume of water sample that can be purified is $4500 \mathrm{ml}$, after which the effluent water quality does not reach the standard especially the concentration of $\mathrm{Fe}$ is excessive. At a lower temperature, when the water samples flow through the resin at $12-13 \mathrm{~m} / \mathrm{h}$, the volume is $3500 \mathrm{ml}$, after which the effluent water quality does not reach the standard.

From the Figure 5 and Figure 6, at lower temperature $\left(4-5^{\circ} \mathrm{C}\right)$, resin has obvious removal effect of iron and manganese. But along with the increase of the temperature, the volume of water the resin could purify to reach the standard also increase. When the amount of effluent is same, water quality under the condition of lower temperature get slightly worse than water quality at normal temperatures. This is the result of the heat bilges and cold shrink, and surface channels of resin are narrowed down as temperature goes down. Some iron molecules could not enter because the large size or the velocities of iron ions moving into the channel or replacing sodium ions decreases. So does resin adsorption of iron and manganese. 


\section{CONCLUSIONS}

Both in a normal and a lower temperature, the resin have obvious effects on the removal of the iron and manganese from the water sample.

At different filtering velocities, the effects of removal by the resin are almost the same, and the higher the filtering velocity is, the larger the volume of the water sample that could be purified to reach the standard by resin is. And temperature does have an effect on the adsorption.

As the temperature goes down, the removal effects by the resin reduces, and the volume of the water sample that could be purified to reach the standard by the resin also decreases.

\section{REFERENCES}

[1] Hao Guo, 2010. The Study of Removal Character and Mechanism of Pb2+by 732Cation Ion Exchange Resin in Sodium Type, A Dissertation Submitted for the Degree of Master.

[2] LIU Da-peng, 2012. Study on adsorption of calcium ion and magnesium ion by 732 cation exchange resin, Textile Auxiliaries, 2012,29(5):39-42.

[3] XiuQin Zhu, 2008. The development and the expectation of technique of the removing iron and manganese from the underground water. Heilongjiang water conservancy science and technology, 2008,36(6):121-122.

[4] Yuhua Zhao, 2009. Study on Removing Iron and Manganese in Ground-Water With Zeolite Modified by $\mathrm{NaOH}$. LiaoNing chemical industry, 2009,38(12):857-860.

[5] $\mathrm{Ru}$ Zheng, 2013.adsorption characteristic study of $\mathrm{Fe} 2+$ and $\mathrm{Mn}+$ from groundwater using biosorbents. A Dissertation Submitted for the Degree of Master.

[6] ZHAO Yuhua. 2011, Effect of Grounder Water Containing Iron and Manganese with Ammonium and Organics Pollutants on the Contact, JOURNAL OF SHENYANG JIANZHU UNIVERSITY NATURAL SCIENCE, 2011,27(4):746-750.

[7] FU Jinxiang. 2008, Oxidation Property of Mixed Bacteria and Their Removal Effect on Iron and Manganese, JOURNAL OF SHENYANG JIANZHU UNIVERSITY NATURAL SCIENCE, 2008,24(2):265-268,273.

[8] ZHAO Yuhua, 2012. Experimental Research of Micro-Chemical Oxidation Treatment of High Iron and Manganese Contaminated Groundwater, JOURNAL OF SHENYANG JIANZHU UNIVERSITY NATURAL SCIENCE，2012,28(6):1098-1102.

[9] FU Jinxiang. 2010, Study on Effect of Co-Existing Fluoride on Oxidation Property of Iron and Manganese Oxidizing Bacteria, JOURNAL OF SHENYANG JIANZHU UNIVERSITY NATURAL SCIENCE, 2010,26(3):534-537.

[10] Pacini, V.H. 2005, Removal of iron and manganese using biological roughing up flow filtation technology. Water Research, 2005,39:4463-4475.

[11] Song Xin, 2010.Removal of iron and manganese from groundwater by two-stage filtration, WATER TECHNOLOGY, 2010,04(5):10-12,20.

[12] Shang Jun,2011.Treatment of micro-polluted groundwater containing iron and manganese by BAF process, WATER TECHNOLOGY, 2011,05(2):8-11.

[13] YANG Wei. 2008, Test about Effect of Iron and Manganese on Nitrogen Transformation in Underground Water, JOURNAL OF SHENYANG JIANZHU UNIVERSITY NATURAL SCIENCE, 2008,24(2):286-290. 